\title{
Miranda
}

Revue pluridisciplinaire du monde anglophone /

Multidisciplinary peer-reviewed journal on the English-

speaking world

15 | 2017

Lolita at 60 / Staging American Bodies

\section{Françoise Clary, Caryl Phillips, Crossing the River}

\section{Christine Dualé}

\section{OpenEdition}

\section{Journals}

Édition électronique

URL : http://journals.openedition.org/miranda/10842

DOI : 10.4000/miranda.10842

ISSN : 2108-6559

Éditeur

Université Toulouse - Jean Jaurès

Référence électronique

Christine Dualé, «Françoise Clary, Caryl Phillips, Crossing the River », Miranda [En ligne], 15 | 2017, mis en ligne le 20 septembre 2017, consulté le 16 février 2021. URL : http://journals.openedition.org/ miranda/10842 ; DOI : https://doi.org/10.4000/miranda.10842

Ce document a été généré automatiquement le 16 février 2021.

\section{c) (i)}

Miranda is licensed under a Creative Commons Attribution-NonCommercial-NoDerivatives 4.0 International License. 


\title{
Françoise Clary, Caryl Phillips, Crossing the River
}

\author{
Christine Dualé
}

\section{RÉFÉRENCE}

Françoise Clary, Caryl Phillips, Crossing the River, Collection Les Clefs concours AnglaisLittérature dirigée par Elisabeth Soubrenie (Paris : Atlande, 2017), 284 p, ISBN :

978-2-35030-384-0

1 Cet ouvrage présente une analyse très riche de Crossing the River, l'œuvre maîtresse de Caryl Phillips qui explore et reconfigure, à travers le récit choral d'une fratrie (deux frères, Nash et Travis et une sœur, Martha), l'histoire de la diaspora noire, les relations Blanc/Noir, dominant/dominé, inclusion/exclusion et «introduit une réflexion sur la transmission de la mémoire » (100). Caryl Phillips est connu et reconnu pour être un auteur de l'Atlantique Noir car ses fictions tissent les multiples expériences de la diaspora noire et explorent toutes ses facettes. L'ouvrage de Françoise Clary met ainsi en regard influences et apports historiques, culturels et littéraires afin d'exprimer une identité noire diasporique hybride et de souligner une écriture du trauma et du nondit. Le présent ouvrage est divisé en trois grands axes (repères; analyses thématiques et synthèse) qui permettront aux étudiants comme à tous ceux intéressés par la littérature postcoloniale et l'identité noire diasporique de réfléchir au concept d'hybridité qu'il soit identitaire, littéraire ou culturel. L'ouvrage va bien au-delà d'une simple analyse littéraire puisque chaque partie (la « synthèse " plus particulièrement) ouvre de multiples pistes de réflexion historique, esthétique et élargit l'analyse à l'imaginaire des poètes de l'espace Caraïbe. En annexes, Françoise Clary présente une chronologie biographique assortie de la réception des œuvres de Caryl Phillips.

2 Les références littéraires, historiques, culturelles ou encore idéologiques et philosophiques abondent dans l'œuvre de Phillips exactement comme la présente étude qui analyse très finement le roman de Caryl Phillips. Cet ouvrage s'avérera donc un 
outil précieux pour les étudiants et/ou candidats à l'agrégation externe. L'entrée dans la littérature afro-caribéenne et dans Crossing the River se fait par une introduction ( Repères ») extrêmement riche et détaillée qui met en regard ce que Françoise Clary nomme « le jeu des convergences » et signale la puissante dynamique de créolisation à travers les différents degrés d'hybridation culturelle. Les Noirs américains et les AfroCaribéens du Royaume-Uni, notamment, forment une communauté autour d'une histoire commune faite de multiples déplacements depuis les rives africaines jusqu'aux colonies anglo-américaines et celles des caraïbes puis dans les colonies elles-mêmes. Parler de diaspora noire renvoie ainsi à de nombreux changements (géographiques, démographiques, politiques, épistémologiques et culturels) dans le monde colonial et postcolonial qui ont participé et participent toujours de la construction identitaire culturelle noire diasporique. Dans The Black Atlantic (1993) Paul Gilroy utilise les termes "créolisation ", "métissage » ou encore "hybridité " pour traduire le syncrétisme culturel et identitaire et souligner les mutations à l'œuvre et le processus de (dis)continuité dans la création culturelle et identitaire noires. Homi Bhabha dans The Location of Culture (1994) voit davantage là ce qu'il nomme la "culture de survie ", témoignage de collisions, d'échanges culturels et portée par des êtres qui évoluent entre tradition et formes culturelles hybrides. En plaçant son roman dans une perspective résolument postcoloniale, Caryl Phillips invite le lecteur à ne pas envisager une fixité identitaire dans le processus d'hybridité et montre comment les concepts polysémiques de «culture " et d'« identité » noires diasporiques se construisent l'un par rapport à l'autre et renvoient aux notions connexes de "diaspora ", de " déterritorialisation ", ou encore de " créolisation ».

3 En définissant le contexte géopolitique dès le début de l'ouvrage, Françoise Clary nous fait comprendre comment l'impérialisme économique de l'Europe et le capitalisme industriel façonnèrent l'identité diasporique africaine tout en imposant une prise de conscience identitaire chez ces êtres déterritorialisés dont l'esclavage nia la mémoire culturelle. La dynamique de créolisation et le cheminement d'êtres de la marge vers la création d'une culture commune, hybride et métissée, sont mis au premier plan. Cette étude permet de prendre toute la mesure de l'espace transatlantique dans la formation de la culture et de l'identité noires diasporiques et de relever les schémas de « mises en relation des cultures, africaine, antillaise, indienne, britannique, américaine » (95) des romans de Phillips. Ces mises en relation renvoient aux « rencontres entre sujets différents mais pas indifférents » évoquées par Edouard Glissant dans Introduction à une poétique du divers (1996). Les influences (culturelles et littéraires) présentes dans Crossing the River montrent, par conséquent, le caractère polymorphe et la fluidité de l'identité culturelle noire qui s'inscrit dans un continuum à la fois individuel et collectif. Elles permettent aussi de présenter toute la richesse de l'écriture elliptique caribéenne, "écriture de l'émotion et du non-dit» (107). Ainsi, Phillips reconfigure l'histoire de la diaspora noire grâce à des histoires fragmentées et asynchrones. La "petite histoire ", c'est-à-dire les tranches de vie de ses héros, est l'occasion pour Phillips de réécrire l'Histoire et d'offrir un regard personnel: "réécrire l'histoire depuis la marge » (147) permet à Phillips d'articuler un contre-discours, de remettre en cause les normes établies et de proposer «la formulation postcoloniale d'une littérature moderniste » (148).

4 Crossing the River, tout comme de nombreux ouvrages appartenant à la littérature afrocaribéenne, présente une synthèse d'apports très divers et attache une importance toute particulière à la fragmentation des êtres mais aussi à leur dislocation ; dislocation 
que le langage ne peut retranscrire. W.E.B. Du Bois fut l'un des premiers intellectuels noirs américains à évoquer, dans The Souls of Black Folk (1903) ainsi que dans Dusk of Dawn (1940), la dislocation géographique et culturelle ainsi que la mémoire de l'esclavage pour expliquer la tension entre les origines et les voies à emprunter. Phillips fait prendre conscience des traumatismes de la diaspora noire et interroge sur cette identité diasporique à travers trois thématiques ("l'humanité du Noir », "la figure féminine», "la religion et la culture»). Il use d'« une narration segmentée à visée allégorique " (111) où la "désaliénation du sujet diasporique va de pair avec un processus de démythification du discours dominant » (111).

5 La structure d'analyse proposée par les éditions Atlande fait écho au style même de l'auteur étudié ici. D'ailleurs, comment ne pas établir un rapprochement avec l'analyse d'une extrême précision de Françoise Clary qui s'approprie l'écriture de Phillips en fusionnant contextes historique, culturel, littéraire, philosophique et idéologique afin de comprendre et d'interroger l'identité diasporique noire. Françoise Clary explique d'abord le contexte géopolitique puis historique de la fiction de Phillips, avant d'amener le lecteur vers les contextes culturel et littéraire et de terminer par une réflexion sur les dimensions esthétiques et politiques du discours culturel afrocaribéen. Comme Caryl Phillips l'expose dans son écriture et comme Françoise Clary s'attache à le montrer, la culture et la littérature noires américaines et afrocaribéennes mettent en jeu d'autres perceptions et différentes strates, au sens deleuzien, qui font sens. Ainsi, la lecture de Crossing the River peut se faire par n'importe quelle section du roman car la narration ne répond pas à un agencement préétabli ; elle s'apparente, en définitive, aux Mille "plateaux» définis par Gilles Deleuze et Félix Guattari. Tous ces plateaux soulignent une multiplicité d'approches, d'influences, d'interprétations.

6 Le concept de "marge ", présent dans l'écriture du roman et caractéristique de la littérature mineure et de la "minoration», permet d'articuler la résistance noire au système hégémonique et de subvertir la norme établie. En prenant ses distances du canon littéraire euro-américain, Caryl Phillips affiche sa volonté « de rompre toute relation de subalternité vis-à-vis de la culture eurocentrique" (188). Par cette réorganisation des codes narratifs, Phillips aboutit à « une esthétique de liberté » (189). La mémoire et l'oubli sont aussi mis en relation à travers une mosaïque d'espaces de mémoire qui souligne, par ailleurs, la proximité de l'auteur avec les romanciers africains et le lien étroit entre texte et intertexte. Caryl Phillips s'appuie sur un espacetemps intermédiaire où l'action, qui est éclatée entre différents espaces, renvoie à un «mouvement vers l'ailleurs» (112). Par conséquent, les concepts d'intersectionnalité de Kimberle Crenshaw, de la marge et du mineur, ou encore du rhizome deleuzien, forment autant de repères théoriques, philosophiques et idéologiques qui aident à comprendre l'écriture polyphonique de Phillips. Ces concepts et cette écriture témoignent de l'identité «rhizomatique» noire et permettent finalement de décloisonner l'analyse en ne la cantonnant pas uniquement aux théories postcoloniales dans lesquelles elle s'inscrit. Le « rhizome » deleuzien ou ce que Françoise Clary nomme la " pluralité en mouvement constant » (184) permet à Phillips d'articuler la différence culturelle et de montrer comment la culture noire diasporique est faite de parcours, d'influences et de réseaux divers qui finissent tous par se télescoper et se nourrir les uns les autres. En articulant hybridation et récits de mémoire collective et individuelle, marge et histoire, déconstruction identitaire et renversement des normes, on retiendra toutes les influences à l'œuvre dans la représentation « du traumatisme de la diaspora 
noire et de sa relation à l'Afrique " (110). L'Afrique, qui est mise à distance et rejetée en tant que référent identitaire par l'un des personnages du roman (Nash), est bien présente à travers la dimension philosophique conférée à l'écriture du non-dit mais aussi à travers la réinterprétation intertextuelle du conte africain qui permet une mise à distance du monde occidental. « Le schéma en ellipse de Crossing the River confirme la correspondance avec la thématique du roman postcolonial africain : savoir affronter les drames et les échecs du passé pour s'ouvrir à l'avenir. [...] Assumer un passé de souffrance, de dislocation et de mort est source de vie » (151). Françoise Clary s'attache à montrer les diverses influences à l'œuvre à travers l'histoire de la diaspora noire et dans l'écriture de Caryl Phillips en soulignant l'intertextualité littéraire, culturelle, historique et philosophique qui jalonne toute la lecture de Crossing the River. Si « la mémoire collective se construit sur une base d'échange dans Crossing the River » (16), le présent ouvrage montre, quant à lui, à quel point l'écriture de Phillips est riche d'échanges et d'emprunts à la fois à la littérature africaine, afro-américaine et afrocaribéenne. "L'idée de déplacement aide à comprendre l'éventail des perspectives offertes par l'œuvre de Phillips nourrie des thématiques majeures de la littérature caribéenne ainsi que la fiction afro-américaine » (91).

7 L'intertextualité de Crossing the River permet à Françoise Clary de tisser des liens et d'établir des ponts entre histoire, littérature, mémoire, construction identitaire, écriture de l'émotion et du non-dit. Ce faisant, elle souligne autour de l'œuvre de Caryl Phillips une "conscience communautaire qui se transmet de personne à personne, d'espace en espace, de groupe en groupe [...] qui caractérise l'écriture diasporique de l'exil et du traumatisme, qu'il soit collectif ou individuel » (21-22). En naviguant ainsi entre les domaines et en décloisonnant les frontières disciplinaires, Françoise Clary fait aisément circuler les savoirs. On soulignera enfin l'apport remarquable de ce travail extrêmement fouillé dans le cadre des études postcoloniales et l'histoire du Commonwealth en France. Cette étude laisse une trace durable en clarifiant les rapports entre l'écriture, le discours culturel et le discours identitaire et ouvre des pistes de réflexion sur l'identité noire diasporique, la valeur symbolique de l'Afrique, la transmission et la mémoire, la déterritorialisation, la fragmentation des êtres et l'influence de la littérature africaine, afro-américaine et afro-caribéenne dans la littérature postcoloniale de l'Atlantique noir.

\section{INDEX}

Mots-clés : culture, créolisation, déterritorialisation, diaspora noire, espace transatlantique, hybridation culturelle, identité(s) noire(s), littérature mineure, marge, rhizome

Keywords : culture, cultural hybridity, creolization, deterritorialization, black diaspora, transatlantic space, black identities, minor literature, margin, rhizome 


\section{AUTEURS}

\section{CHRISTINE DUALÉ}

Maître de conférences HDR

Université Toulouse Capitole

christine.duale@ut-capitole.fr 